\title{
The Inhibition Effect of Ampicillin on Corrosion of Pure Aluminium in 3.5\% NaCl Aqueous Solution
}

\author{
Samar T. Hameed ${ }^{1}$, Taghried A. Salman and Shatha F. Al-Saidi \\ Department of Chemistry, College of Science, Al-Nahrain University, Baghdad-Iraq. \\ ${ }^{1}$ E-mail: samar.thamer@gmail.com.
}

\begin{abstract}
The Inhibition of the corrosion of pure aluminium in $3.5 \% \mathrm{NaCl}$ aqueous solution using ampicillin has been studied using potentiodynamic polarization and scanning electron microscopy (SEM) techniques. It was found that the ampicillin effectively reduces the aluminium corrosion in the saline solution. Inhibition efficiency (\%IE) is increased as the inhibitor concentration increases; on the other hand, (\% IE) is decreased when the temperature increases. The adsorption of inhibitor on metal surface was spontaneous and follows Langmuir adsorption isotherm. Quantum mechanical has been accomplished using B3LYP/6-31G basis set method to ascertain any correlation between the inhibitive effect and molecular structure of ampicillin.
\end{abstract}

Keywords: Aluminium, saline solution, Corrosion inhibitor, Ampicillin, Quantum studie.

\section{Introduction}

Aluminum is an important metal in industry owing to its many excellent characteristics including its good electrical and thermal conductivities, low density, high ductility, and good corrosion resistance. It is widely used as a material for automobiles, aviation, household appliances, and containers [1]. In spite of these attractive properties of aluminium, in the presence of aggressive ions, like chloride, the protective layer can be locally destroyed and corrosive attack takes place [2]. Corrosion control and prevention are unavoidable major scientific issues that must be addressed daily as far as there are increasing applications of metallic materials in all facets of technological development [3].

The main corrosion issue with aluminium and its alloys is the localized breakdown of the passive film, which leads to the initiation and growth of corrosion pits in chloride medium [4]. Using inhibitors is an effective method to reduce corrosion rate [5].Chemical inhibitors play an important role in the protection and mitigation strategies for retarding corrosion [6]. Corrosion inhibitors generally organic compounds containing $\mathrm{N}, \mathrm{O}, \mathrm{S}$ heteroatoms ormstructures containing $\pi$ electrons in their molecules[7]. Inhibitors decrease the corrosion rate by adsorbing on the metal surface and blocking the active sites by displacing water molecules and form a compact barrier film on the metal surface [8]. The choice of some of the drugs used as corrosion inhibitors is based on the following facts (a) the molecules have oxygen, nitrogen and sulphur as active centers, (b) they are healthy and reportedly very important in biological reactions (i.e. not hazardous and environmentally friendly) and (c) they can be easily produced and purified[9]. The present work study the corrosion protection action of Ampicillin on aluminium in $3.5 \% \mathrm{NaCl}$ aqueous solution using electrochemical techniques. Ampicillin (6-[2-amino-2-phenylacetamide] penicillanicacid), Fig.(1). The molecule is big enough (Molecular Mass: $349.40 \mathrm{~g} \mathrm{~mol}^{-1}$ ) and sufficiently planar to block more surface area (due to adsorption) on aluminium. These factors favor the interaction of AMP with the metal surface. As far as we know no concrete report has been published for aluminium corrosion inhibition by AMP in saline aqueous solution.

The aim of the present work is to study inhibiting action of ampicillin on aluminium metal in $3.5 \%$ of aggressive $\mathrm{NaCl}$ aqueous solution in various concentrations. Thermodynamic parameters such as enthalpy, entropy and Gibbs free energy for adsorption were obtained from the experimental data of the inhibition process at different temperatures, and pre-exponential factor at various inhibitor concentrations were calculated. The effect of activation energy on the corrosion rate of aluminium was discussed. The inhibition mechanism has been also discussed based on the electron orbital density 
distribution of highest occupied molecular orbital (HOMO), lowest unoccupied molecular orbital (LUMO), energy gap, dipole moment, and total energy of ampicillin molecule.

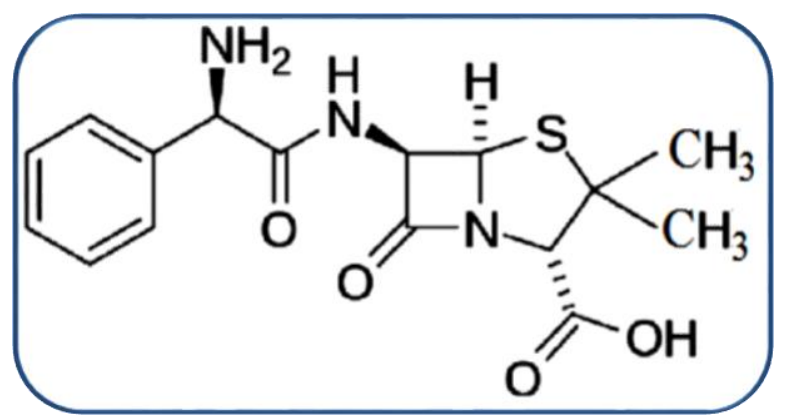

Fig.(1) The chemical Structure of ampicillin.

\section{Experimental}

\section{Materials and Sample Preparation}

The aluminium sample selected for the study was of high purity (99.99\%). Prior to each electrochemical experiment, the test specimen was polished with emery paper in different grades $(320,500,1000,2400,4000)$ with diamond product spray (DP Spray, HQ, High quality diamond product (struers)) that contain ethanol with different size of diamond particles $(1 \mu \mathrm{m}, 3 \mu \mathrm{m}, 6 \mu \mathrm{m}, 9 \mu \mathrm{m})$, then washed with acetone and finally rinsed with distilled water. The aggressive solution of sodium chloride (AR grade) supplied from (EDUTEK), was used for this study. Ampicillin (99\% purity), with chemical formula, $\mathrm{C}_{16} \mathrm{H}_{19} \mathrm{~N}_{3} \mathrm{O}_{4} \mathrm{~S}$, (Ampicillin sodium salt trihydrate powder) was purchased from Samarra Drugs Manufacture and used without further purification. Distilled water was used for the preparation of all solutions. In each experiment, $3.5 \% \mathrm{NaCl}$ solution was freshly prepared as required while the concentrations of the inhibitor (ampicillin) were $\left(1.5 \times 10^{-4}\right.$, $3 \times 10^{-4}, 4.5 \times 10^{-4}, 6 \times 10^{-4}$ and $\left.7.5 \times 10^{-4} \mathrm{M}\right)$.

\section{Potentiodynamic Polarization Measurements}

The working electrode (WE) used in this study was pure aluminum, the reference electrode (RE) was Saturated Calomel Electrode (SCE), the auxiliary electrode was platinum type. The specimen holder (working electrode), together with the reference and auxiliary electrodes were inserted in their respective positions in the electrochemical cell used that was made of glass, The reference electrode was fixed about $1 \mathrm{~mm}$ away from the surface of the specimen to be tested. The aerated and stirred electrolyte used with the volume of $1 \mathrm{~L}$.

Constant potentials (anodic or cathodic) can beimpressed on the specimen, by using the potentiostat (WENKING MLab multichannel and SCI-MLab corrosion measuring system from Bank Electronics- Intelligent controls $\mathrm{GmbH}$, Germany 2007). This potentiostat is able to induce a constant potential ranging from $-2 \mathrm{~V}$ to $+2 \mathrm{~V}$, for the standard reference electrode used in this study. The potential difference between the working electrode (WE), the reference electrode (RE), and any current passing in the circuit of the working electrode and auxiliary electrode can be automatically recorded by using the MLabSci computer software using Window XP. The scan rate can be selected also. In the tests, cell current reading was taken during a short, slow sweep of the potential. The sweep was taken from $-200 \mathrm{mV}$ to $+200 \mathrm{mV}$ relative to open circuit potential (OCP). The scan rate defines the speed of potential weep in $\mathrm{mV} / \mathrm{sec}$. in this range.

\section{Quantum Chemical Calculations}

Quantum calculations were implemented in Gaussian 09W program package using the density functional theory (DFT) with Beck's three parameter exchange functional along with Lee-Yang-Parr non-local correlation functional (B3LYP) with 6-31G basis set. The energy of the highest occupied molecular orbital (ЕНомо), the lowest unoccupied molecular orbital ( $\left.\mathrm{E}_{\text {LUMO }}\right)$, energy gap $(\Delta \mathrm{E})$, dipole moment $(\mu)$, and total energy $(\mathrm{ET})$ of the inhibitor were calculated by the above given computer code package.

\section{Scanning Electron Microscopy (SEM) Analysis}

The scanning electron microscope images of the aluminium samples were recorded via FEI Inspect-S50 scanning electron microscope. 


\section{Results and Discussion}

Potentiodynamic Polarization Measurements Tafel Polarization

The electrochemical results of aluminium sample in inhibited and uninhibited solutions are presented in Fig.(3) and listed in Table(1). The data obtained including the corrosion potential $\left(\mathrm{E}_{\text {corr }}\right)$, and corrosion current densities $\left(i_{\text {corr }}\right)$, the anodic $\left(b_{a}\right)$ and cathodic $\left(b_{c}\right)$ Tafel slopes in $3.5 \%$ of $\mathrm{NaCl}$ aqueous solution for various concentrations of ampicillin at different five temperatures ranging (283-323 K). Results of the cathodic and anodic curves demonstrated a Tafel type behavior. The presence of ampcillin significantly changes both anodic $\left(b_{a}\right)$, and cathodic $\left(b_{c}\right)$ region compared to the absence of inhibitor. These results agreed with Singh et al. [10]. Thus, cathodic and anodic reactions were interfered in the presence of ampicillin. This implies that the ampicillin showed an effective inhibition on cathodic hydrogen reduction reaction, and anodic dissolution of aluminium. Also, the results indicate that ampicillin acts as a mixed type inhibitor. This can be explained on the basis of specific adsorption of ampicillin and on the basis of the competitive adsorption between the ampicillin and chloride ions on the aluminium surface, that causes retard the chloride ions destructive action. Apparently, the bond between the surface atoms of the metal and the adsorbed inhibitor anions is strong, which can inhibit oxidation [11]. The corrosion potential $\left(E_{\text {corr. }}\right)$ shifted to the more negative values in the presence of inhibitor. From Table (1), it is clear that the corrosion current density ( $\left.i_{\text {corr. }}\right)$ decreases with increasing concentrations of ampcillinin $3.5 \%$ of $\mathrm{NaCl}$ aqueous solution. On the other hand, ( $i_{\text {corr. }}$ ) increases with increasing temperatures.

Anodic and cathodic processes of aluminium corrosion in saline solution are dissolution of aluminium and reduction of dissolved oxygen, respectively [12].

$$
\begin{aligned}
& 4 \mathrm{Al} \rightarrow 4 \mathrm{Al}^{3+}+12 \mathrm{e}^{-} \quad \text { (anodic) } \ldots . . . . . . . . . \\
& 3 \mathrm{O}_{2}+6 \mathrm{H}_{2} \mathrm{O}+12 \mathrm{e}^{-} \rightarrow 12 \mathrm{OH}^{-} \text {(cathodic) }
\end{aligned}
$$

Therefore, aluminium ions $\left(\mathrm{Al}^{3+}\right)$ react with hydroxide ions $\left(\mathrm{OH}^{-}\right)$to form aluminum hydroxide near the aluminium surface as follows:

$$
4 \mathrm{Al}+3 \mathrm{O}_{2}+6 \mathrm{H}_{2} \mathrm{O} \rightarrow 4 \mathrm{Al}(\mathrm{OH})_{3}
$$




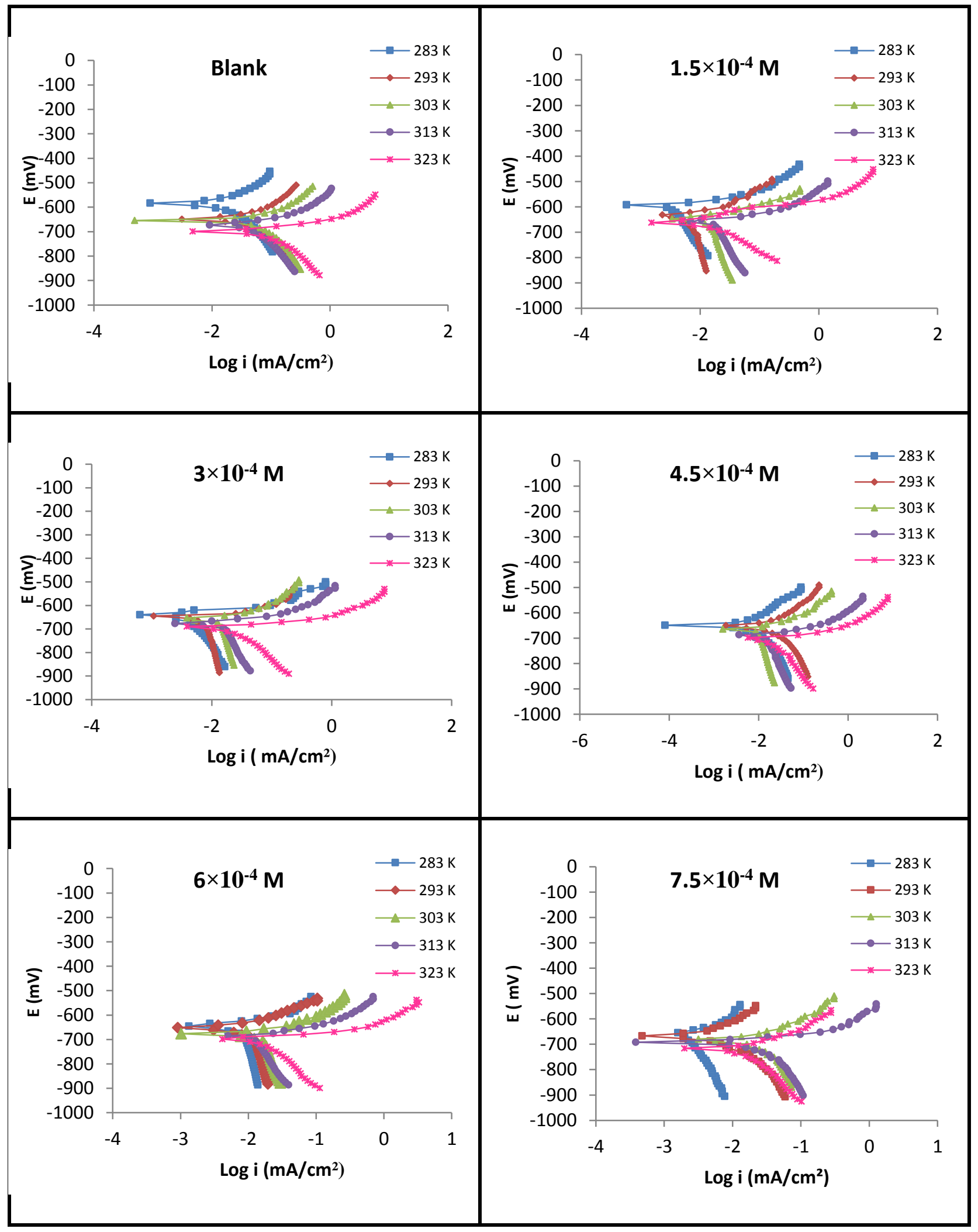

Fig.(3) Polarization curves for the corrosion of pure aluminium without, with various concentrations of ampicillin in $3.5 \%$ of $\mathrm{NaCl}$ aqueous solution at different temperatures. 
Table (1)

Potentiodynamic polarization parameters for pure aluminium without and with various concentrations of ampicillin in $3.5 \%$ of $\mathrm{NaCl}$ aqueous solution at different temperatures.

\begin{tabular}{|c|c|c|c|c|c|c|c|c|c|}
\hline 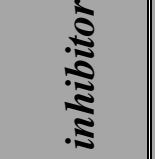 & نे & $\begin{array}{c}T \\
{[K]}\end{array}$ & $\begin{array}{l}\text {-Ecorr } \\
{[m V]}\end{array}$ & $\begin{array}{c}\text { Icorr } \\
{\left[\mu A / \mathrm{cm}^{2}\right]}\end{array}$ & $\begin{array}{c}-b c \\
{[m V / D e c]}\end{array}$ & $\begin{array}{c}b a \\
{[m V / D e c]}\end{array}$ & $\theta$ & $\% I E$ & $\begin{array}{c}R_{p} / 10^{3} \\
{\left[\Omega / \mathrm{cm}^{2}\right]}\end{array}$ \\
\hline \multirow{5}{*}{ 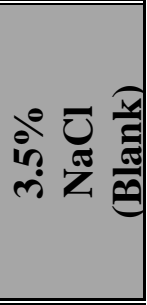 } & \multirow{5}{*}{0} & 283 & 642.8 & 13.33 & 146.8 & 41.9 & - & - & 1.06 \\
\hline & & 293 & 651.0 & 16.42 & 164.2 & 54.6 & - & - & 1.08 \\
\hline & & 303 & 655.9 & 36.65 & 165.1 & 96.2 & - & - & 0.72 \\
\hline & & 313 & 660.1 & 47.88 & 337.5 & 100.1 & - & - & 0.70 \\
\hline & & 323 & 686.4 & 54.47 & 385.7 & 104.2 & - & - & 0.65 \\
\hline \multirow{25}{*}{$\sum_{i}^{\dot{e}}$} & \multirow{5}{*}{$\begin{array}{l}\stackrel{+}{0} \\
\stackrel{x}{x} \\
\stackrel{n}{-}\end{array}$} & 283 & 595.0 & 3.72 & 149.1 & 48.6 & 0.72 & 72.09 & 4.28 \\
\hline & & 293 & 633.0 & 4.78 & 289.2 & 52.3 & 0.71 & 70.91 & 4.03 \\
\hline & & 303 & 647.0 & 11.98 & 305.0 & 73.0 & 0.67 & 67.32 & 2.14 \\
\hline & & 313 & 658.7 & 17.10 & 358.8 & 99.2 & 0.64 & 64.29 & 1.97 \\
\hline & & 323 & 662.2 & 19.90 & 419.0 & 105.2 & 0.63 & 63.47 & 1.83 \\
\hline & \multirow{5}{*}{ 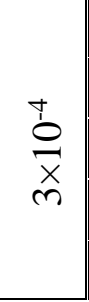 } & 283 & 639.6 & 3.49 & 142.2 & 48.3 & 0.74 & 73.82 & 4.49 \\
\hline & & 293 & 646.2 & 4.46 & 229.6 & 56.2 & 0.73 & 72.81 & 4.39 \\
\hline & & 303 & 655.2 & 11.31 & 233.7 & 75.0 & 0.69 & 699.12 & 2.18 \\
\hline & & 313 & 679.2 & 15.37 & 316.3 & 90.5 & 0.68 & 67.89 & 1.99 \\
\hline & & 323 & 690.8 & 17.90 & 402.3 & 100.4 & 0.67 & 67.12 & 1.95 \\
\hline & \multirow{5}{*}{$\begin{array}{l}\stackrel{+}{0} \\
x \\
\stackrel{x}{+}\end{array}$} & 283 & 647.3 & 2.36 & 130.2 & 33.7 & 0.82 & 82.30 & 4.93 \\
\hline & & 293 & 651.8 & 3.24 & 135.3 & 49.0 & 0.80 & 80.28 & 4.84 \\
\hline & & 303 & 664.2 & 8.57 & 138.1 & 69.9 & 0.77 & 76.62 & 2.35 \\
\hline & & 313 & 686.3 & 11.31 & 241.1 & 75.6 & 0.76 & 76.38 & 2.21 \\
\hline & & 323 & 696.1 & 14.48 & 367.0 & 93.7 & 0.73 & 73.41 & 2.24 \\
\hline & \multirow{5}{*}{\begin{tabular}{l}
+ \\
\multirow{x}{x}{}
\end{tabular}} & 283 & 648.1 & 2.12 & 128.4 & 30.3 & 0.84 & 84.10 & 5.02 \\
\hline & & 293 & 658.5 & 2.89 & 123.5 & 45.0 & 0.82 & 82.39 & 4.95 \\
\hline & & 303 & 676.4 & 7.74 & 126.8 & 66.4 & 0.79 & 78.87 & 2.44 \\
\hline & & 313 & 688.2 & 11.12 & 224.1 & 78.4 & 0.77 & 76.79 & 2.27 \\
\hline & & 323 & 698.0 & 13.22 & 382.6 & 84.6 & 0.76 & 75.73 & 2.28 \\
\hline & \multirow{5}{*}{$\begin{array}{l}\stackrel{t}{o} \\
\dot{x} \\
n \\
r\end{array}$} & 283 & 655.6 & 1.92 & 118.1 & 28.2 & 0.86 & 85.60 & 5.15 \\
\hline & & 293 & 667.2 & 2.51 & 102.4 & 45.3 & 0.85 & 84.71 & 5.43 \\
\hline & & 303 & 679.1 & 5.67 & 112.4 & 51.9 & 0.85 & 84.54 & 2.72 \\
\hline & & 313 & 690.4 & 8.85 & 173.4 & 65.8 & 0.82 & 81.51 & 2.34 \\
\hline & & 323 & 715.5 & 10.64 & 302.7 & 71.0 & 0.80 & 80.47 & 2.35 \\
\hline
\end{tabular}

\section{Polarization Resistance}

The polarization resistance (Rp) was calculated using Stern- Geary equation [13]:

$\mathrm{R}_{\mathrm{p}}=\frac{\mathrm{b}_{\mathrm{a}} \cdot \mathrm{b}_{\mathrm{c}}}{2.303\left(\mathrm{~b}_{\mathrm{a}}+\mathrm{b}_{\mathrm{c}}\right) \mathrm{i}_{\mathrm{corr}}}$ where $b_{a}, b c$ are the anodic and cathodic Tafel slopes respectively, and $\mathrm{i}_{\text {corr }}$ is the corrosion current density. Table (1) shows values of the polarization resistance $\mathrm{R}_{\mathrm{P}}\left(\Omega \mathrm{cm}^{2}\right)$ of aluminium in $3.5 \% \mathrm{NaCl}$ 
aqueous solution over the experimental solution concentrations of ampicillin and temperatures. The results indicate that the $R_{p}$ values decreased with increasing temperature, and increased with increasing concentration of ampicillin. The increase in the $R_{p}$ value suggests that the inhibition efficiency increases with increase in the inhibitor concentration, while the decreases of $R_{p}$ value with increasing temperature suggests that the inhibition efficiency decreases with increasing temperature this confirm a physical adsorption of ampicillin on aluminium surface.

\section{Surface coverage and inhibition efficiency}

The degree of surface coverage $(\theta)$ and inhibition efficiency (\% IE) of the aluminium in $3.5 \% \mathrm{NaCl}$ in the presence of ampicillin with different concentrations and five experimental temperatures were calculated using equations 5 and 6 respectively and the results are given in Table 1.

$\theta=1-\left(\mathrm{i}_{2} / \mathrm{i}_{1}\right)$

$\% \mathrm{IE}=100 \times\left[1-\left(\mathrm{i}_{2} / \mathrm{i}_{1}\right)\right]$

Where $i_{1}$ and $i_{2}$, are the corrosion current densities in the absence and presence of ampicillin in $3.5 \%$ of $\mathrm{NaCl}$ aqueous solution respectively [12].

Generally For a physical adsorption mechanism, inhibition efficiency of an inhibitor decreases with temperature, while for a chemical adsorption mechanism, values of inhibition efficiency increase with temperature [9]. The inhibition efficiency values Table (1) showed that the Ampicillin acted as very effective corrosion inhibitor for aluminiumin $3.5 \% \mathrm{NaCl}$ aqueous solution. The capacity of inhibition increased with increasing concentration. The maximum inhibition efficiency reaches to $(85 \%)$ at the concentration of $7.5 \times 10^{-4} \mathrm{~mol} \mathrm{L^{-1 }}$ AMP. However, the inhibition efficiencies of ampicillin decreases at increasing temperature indicating that ampicillin is a physical adsorption inhibitor for aluminium.

\section{Kinetic parameters}

Arrhenius equation was used (equation 7) to study the effect of temperature on the inhibited corrosion reaction of aluminium, [14] $\log i_{\text {corr. }}=\log A-E_{a} / R T$

where $E_{a}$ is the energy activation of the corrosion reaction $\left(\mathrm{kJ} \mathrm{mol}^{-1}\right)$ and $\mathrm{A}$ is the pre-exponential factor (inmolecules $\mathrm{cm}^{-2} \mathrm{~s}^{-1}$ ), $\mathrm{R}$ is the gas constant and $\mathrm{T}$ is the temperature (Kelvin).

Values of $E_{a}$ were derived from the slopes of linear relationship between ( $\left.\log \mathrm{i}_{\text {corr }}\right)$ versus (1/T), Fig.(4), while (A) obtained from the intercepts. The entropy of activation $\left(\Delta \mathrm{S}^{*}\right)$ is related to the pre-exponential factor (A) as [15]:

$\mathrm{A}=\mathrm{k} \mathrm{T} / \mathrm{h} \exp (\Delta \mathrm{S} * / \mathrm{R})$

Where $\mathrm{k}$ is Boltzmann constant, $\mathrm{T}$ the temperature in (Kelvin), and $\mathrm{h}$ is Plank's constant. Table (2) shows the values of the activation energy $\left(E_{a}\right)$, pre-exponential factor (A), and entropy of activation $\left(\Delta \mathrm{S}^{*}\right)$ of aluminium in the absence and presence of various concentrations of ampicillin. All $E_{a}$ values are higher than the value of the blank $(29.674 \mathrm{~kJ} / \mathrm{mol})$ indicating that the corrosion reaction of aluminium is retarded by ampicillin. It also supports the phenomenon of physical adsorption [16].

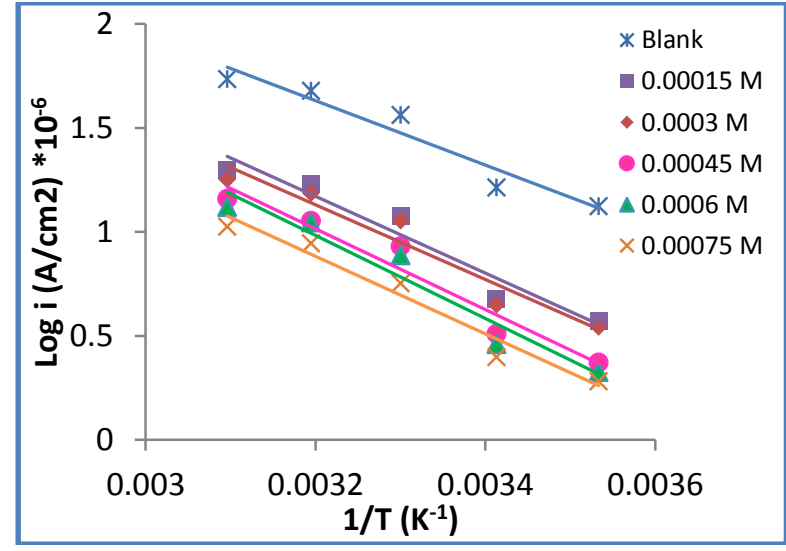

Fig. (4) Arrhenius plots of log $i_{\text {corr }}$ versus $1 / T$ for aluminium in $3.5 \% \mathrm{NaCl}$ aqueous solution in the absence and the presence of different concentrations of AMP. 
Table (2)

Activation energy $\left(E_{a}\right)$, pre exponential factor $(A)$, and the entropy of activation $(\Delta S *)$ for the corrosion of pure aluminum in 3.5\% $\mathrm{NaCl}$ aqueous solution in the absence and presence of different concentration of AMP at different temperatures.

\begin{tabular}{|c|c|c|c|c|c|c|}
\hline inhibitor & $\begin{array}{c}\text { Conc. } \\
{[M]}\end{array}$ & $\begin{array}{c}T \\
{[K]} \\
\end{array}$ & $R^{2}$ & $\begin{array}{c}E \boldsymbol{E} a \\
{\left[\mathrm{~kJ} . \mathrm{mol}^{-1}\right]} \\
\end{array}$ & $\begin{array}{c}A \\
\left.\text { [molecule.cm }{ }^{-2} \cdot \mathrm{s}^{-1}\right] \\
\end{array}$ & $\begin{array}{c}\Delta s^{*} \\
{\left[J . K^{-1} \cdot \mathrm{mol}^{-1}\right]} \\
\end{array}$ \\
\hline \multirow{5}{*}{$\begin{array}{l}\mathrm{NaCl} \\
\text { blank }\end{array}$} & \multirow{5}{*}{0} & 283 & \multirow{5}{*}{0.934} & \multirow{5}{*}{29.674} & \multirow{5}{*}{$2.414 \times 10^{25}$} & 241.485 \\
\hline & & 293 & & & & 241.196 \\
\hline & & 303 & & & & 240.917 \\
\hline & & 313 & & & & 240.647 \\
\hline & & 323 & & & & 240.386 \\
\hline \multirow{25}{*}{ AMP. } & \multirow{5}{*}{$1.5 \times 10^{-4}$} & 283 & \multirow{5}{*}{0.941} & \multirow{5}{*}{34.425} & \multirow{5}{*}{$4.378 \times 10^{25}$} & 246.437 \\
\hline & & 293 & & & & 246.148 \\
\hline & & 303 & & & & 245.869 \\
\hline & & 313 & & & & 245.599 \\
\hline & & 323 & & & & 245.337 \\
\hline & \multirow{5}{*}{$3 \times 10^{-4}$} & 283 & \multirow{5}{*}{0.935} & \multirow{5}{*}{35.336} & \multirow{5}{*}{$4.745 \times 10^{25}$} & 247.105 \\
\hline & & 293 & & & & 246.816 \\
\hline & & 303 & & & & 246.537 \\
\hline & & 313 & & & & 246.267 \\
\hline & & 323 & & & & 246.006 \\
\hline & \multirow{5}{*}{$4.5 \times 10^{-4}$} & 283 & \multirow{5}{*}{0.948} & \multirow{5}{*}{35.700} & \multirow{5}{*}{$7.389 \times 10^{25}$} & 250.789 \\
\hline & & 293 & & & & 250.500 \\
\hline & & 303 & & & & 250.221 \\
\hline & & 313 & & & & 249.951 \\
\hline & & 323 & & & & 249.689 \\
\hline & \multirow{5}{*}{$6 \times 10^{-4}$} & 283 & \multirow{5}{*}{0.944} & \multirow{5}{*}{37.258} & \multirow{5}{*}{$1.083 \times 10^{26}$} & 253.967 \\
\hline & & 293 & & & & 253.679 \\
\hline & & 303 & & & & 253.399 \\
\hline & & 313 & & & & 253.129 \\
\hline & & 323 & & & & 252.868 \\
\hline & \multirow{5}{*}{$7.5 \times 10^{-4}$} & 283 & \multirow{5}{*}{0.962} & \multirow{5}{*}{38.243} & \multirow{5}{*}{$1.470 \times 10^{26}$} & 256.510 \\
\hline & & 293 & & & & 256.221 \\
\hline & & 303 & & & & 255.942 \\
\hline & & 313 & & & & 255.672 \\
\hline & & 323 & & & & 255.411 \\
\hline
\end{tabular}

\section{Adsorption Consideration and}

\section{Thermodynamic parameters}

The primary step in the action of inhibitors is their adsorption on the metal surface. The adsorbed inhibitor then acts to retard the cathodic and/or anodic electrochemical corrosion reaction. Basic information on the interaction between the inhibitor and the aluminium surface can be provided by the adsorption isotherm. In this study, Langmuir adsorption isotherm was found best for describing the adsorption behavior of Ampicillin on the aluminium in $3.5 \% \mathrm{NaCl}$ aqueous solution. Langmuir adsorption isotherm is described by the following equation [5]:

$[\theta /(1-\theta)]=K_{\text {ads }}\left[C_{\text {inh }}\right]$ 
where $\mathrm{K}_{\mathrm{ads}}$ is the equilibrium constant of the adsorption process, $\theta$ is surface coverage and $\mathrm{C}_{\mathrm{inh}}$ is the inhibitor concentration.

The dependence of the fraction $\mathrm{C}_{\mathrm{inh}} / \theta$ as a function of $\mathrm{C}_{\mathrm{inh}}$ for AMP is shown Fig.(5). The obtained plots of the inhibitor are almost linear. The equilibrium constant of adsorption $\mathrm{K}_{\mathrm{ads}}$ is related to the standard free energy of adsorption $\Delta \mathrm{G}_{\mathrm{ads}}$, according to the following equation [18]:

$\mathrm{K}_{\mathrm{ads}}=1 / 55.5 \exp \left(-\Delta \mathrm{G}_{\mathrm{ads} .} / \mathrm{RT}\right)$

Where 55.5 is the concentration of water in solution expressed in $\mathrm{M}$, and $\mathrm{R}$ is the gas constant, $\mathrm{T}$ is the absolute temperature.

Generally, the values of $\Delta \mathrm{G}_{\text {ads. }}$ around $-20 \mathrm{~kJ} \mathrm{~mol}^{-1}$ or less negative are consistent with electrostatic interaction (physisorption), while those $-40 \mathrm{~kJ} \mathrm{~mol}^{-1}$ and more negative involve electron transfer to form chemical bond (chemisorptions) [19]. The higher value of the equilibrium constant which obtained from the Langmuir isotherm is $\left(\mathrm{K}_{\mathrm{abs}}=17486 \mathrm{~L}\right.$ $\mathrm{mol}^{-1}$ ). The high value of $\mathrm{K}_{\mathrm{ads}}$ for (AMP.) indicates stronger adsorption on the aluminium surface in $3.5 \% \mathrm{NaCl}$ aqueous solution. The calculated value of $\Delta \mathrm{G}_{\mathrm{ads}}$ was $\left(-36 \mathrm{KJ} \mathrm{mol}^{-1}\right)$ which is consistent with the spontaneity of the adsorption process of AMP and the stability of the adsorbed layer on the aluminium surface. The later value is negatively less than the threshold value of $-40 \mathrm{KJ} \cdot \mathrm{mol}^{-1}$, which is required for chemical adsorption. The value of $\Delta \mathrm{G}_{\text {ads. }}$ obtained in this work indicates that the adsorption of AMP is not merely physisorption nor chemisorption. Therefore, this value of $\Delta \mathrm{G}_{\text {ads }}$ confirms that the adsorption of AMP is not a simple physisorption but it may involve some other interactions [20]. Thus, the mechanism of corrosion inhibition of aluminium in saline aqueous solution by AMP could be explained on the basis of adsorption on the metal surface. Physisorption originates from electrostatic interactions of charged molecules with positively charged surface metal while chemisorption involves donoracceptor interactions between $\pi$ electrons of aromatic molecules and free electron pairs of heteroatoms ( $\mathrm{N}, \mathrm{S}$, and $\mathrm{O}$ ) and vacant d-orbitals of metal atoms to form coordinate type bond [21]. Therefore, the nature of interactions between the metal and AMP. molecules are physisorption and chemissorption adsorption or mixed mode of adsorption may occur.

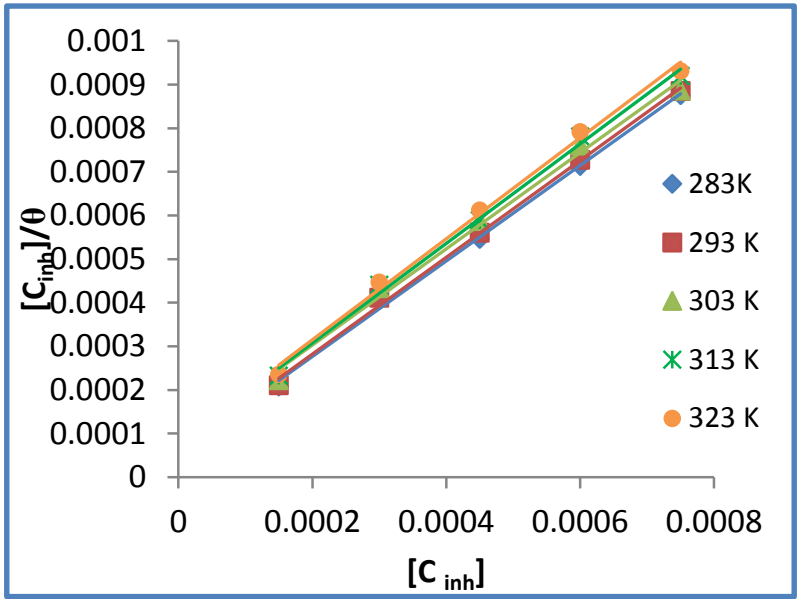

Fig.(5) Langmuir isotherm plot for the adsorption of AMP. on the surface of Alumimium.

Table (3)

Thermodynamic parameters for adsorption of the inhibitors on the surface of pure aluminum in $3.5 \% \mathrm{NaCl}$ aqueous solution.

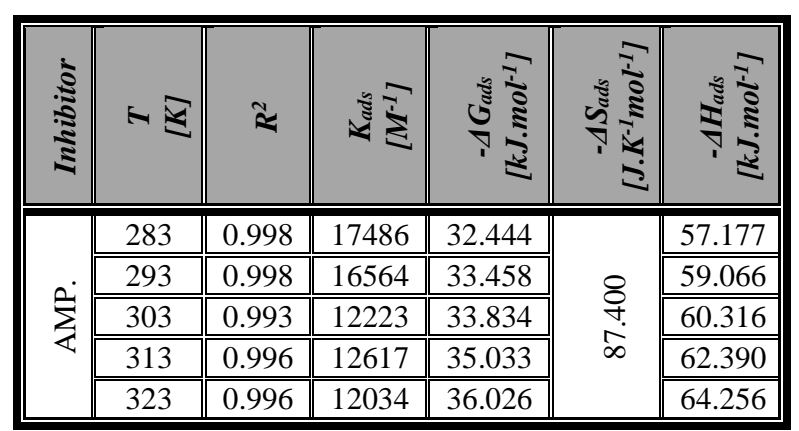

Finally, Thermodynamic parameters were obtained from Gibbs-Helmholtz equation according to the following equation [22]:

$\Delta \mathrm{G}_{\mathrm{ads}}=\Delta \mathrm{H}_{\mathrm{ads}}-\mathrm{T} \Delta \mathrm{S}_{\mathrm{ads}}$

Plots of $\Delta \mathrm{G}_{\mathrm{ads}}$ vs. $\mathrm{T}$ gave straight lines of slope $\Delta \mathrm{S}_{\text {ads.as }}$ shown in Fig.(6). The negative value of $\Delta \mathrm{H}_{\mathrm{ads}}$ means that the adsorption process is an exothermic phenomenon. It is assumed that an exothermic process is attributed to either physical or chemical adsorption but endothermic process corresponds solely to chemisorption. In an exothermic process, physisorption is distinguished from chemisorption by considering the absolute value of $\Delta \mathrm{H}_{\text {ads }}$.

For a physisorption process $\Delta \mathrm{H}_{\mathrm{ads}}$ is lower than $40 \mathrm{~kJ} \mathrm{~mol}^{-1}$ while the adsorption 
heat of a chemisorption process approaches $100 \mathrm{~kJ} \mathrm{~mol}^{-1}$. In this study; the average value of adsorption heat is $\left(-60.641 \mathrm{~kJ} \mathrm{~mol}^{-1}\right)$ this support mixed mode of adsorption of AMP. on aluminium surface [23].

The negative values of $\Delta \mathrm{S}_{\mathrm{ads}}$ indicate that the adsorption is a process accompanied by a reduction in entropy. The negative values of might be explained in the following way: before the adsorption of inhibitor onto the aluminium surface, inhibitor molecules might freely move in the bulk solution but with the progress in the adsorption, inhibitor molecules orderly adsorbed onto the aluminium surface, as a result, a decrease in entropy [24] .

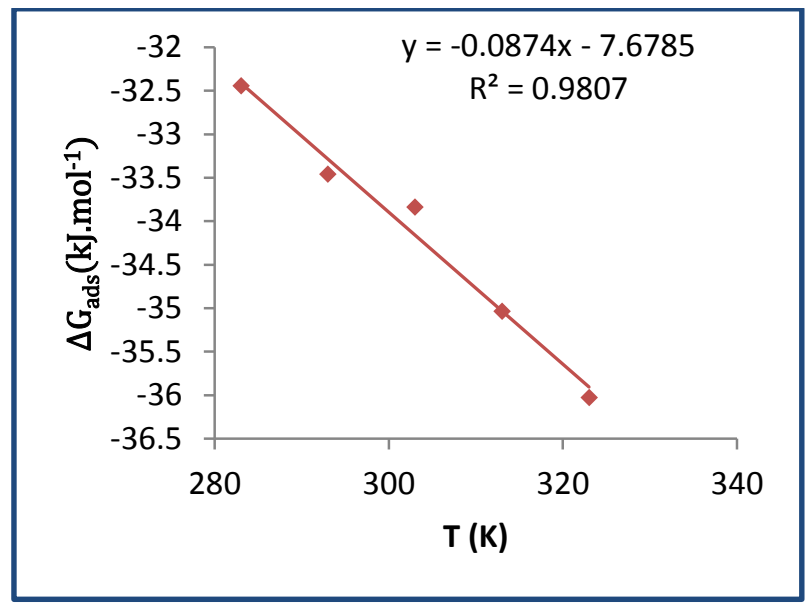

Fig.(6) The variation of Gibbs free energies $\left(\Delta G_{a d s}\right)$ with temperature.

\section{Theoretical calculations}

Quantum chemical methods have already proven to be very useful in determining the molecular structure as well as explain the electronic structure and reactivity [25]. So, it has become a common practice to carry out quantum chemical calculations in corrosion inhibition studies.

Some quantum chemical parameters, which influence the electronic interaction between atoms of surface and inhibitor are the energy of the highest occupied molecular orbital ( $\left.\mathrm{E}_{\mathrm{HOMO}}\right)$, the energy of the lowest unoccupied molecular orbital (ELUMO), the energy gap Elumo- $_{\text {Lhomo }}(\Delta \mathrm{E})$, dipole moment $(\mu)$ and total energy (TE) which are listed in Table (4). These quantum parameters were obtained often complete the optimization of molecular model of AMP. (See Fig.(7)).

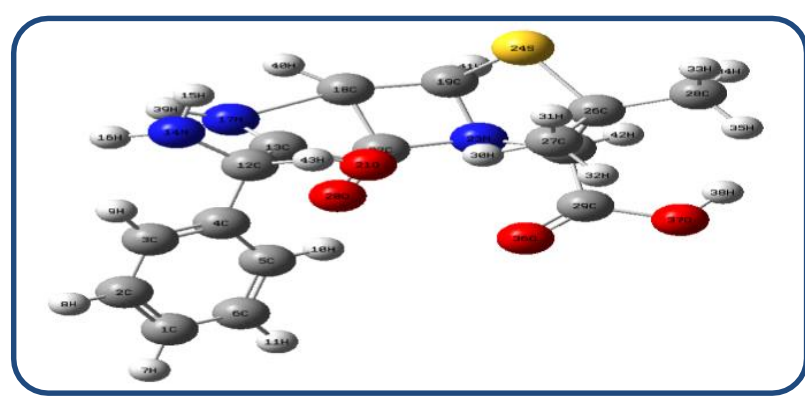

Fig.(7) Optimized structure of ampicillin.

Table (4)

Quantum parameters of AMP.

\begin{tabular}{||c||c||}
\hline \hline Quantum Parameters & Values \\
\hline \hline TE $(\mathrm{eV})$ & -40379.9065 \\
\hline $\mathrm{E}_{\text {HOMO }}(\mathrm{eV})$ & -6.0145 \\
\hline $\mathrm{E}_{\mathrm{LUMO}}(\mathrm{eV})$ & -2.8588 \\
\hline$\Delta \mathrm{E}_{\mathrm{gap}}(\mathrm{eV})$ & 3.1557 \\
\hline$\mu($ Debye $)$ & 4.2155 \\
\hline
\end{tabular}

High values of Еномо indicate a tendency of the molecule to donate electrons to appropriate acceptor molecules with lowenergy, empty molecular orbital. Increasing values of the Еномо facilitate adsorption (and therefore inhibition) by influencing the transport process through the adsorbed layer. The energy of the ELUMO indicates the ability of the molecule to accept electrons. The lower the value of $\mathrm{E}_{\mathrm{LUMO}}$, the more probable, it is that the molecule would accept electrons [26]. As for the values of $\Delta \mathrm{E}$ (ELUMo-Eномо) concern; lower values of the energy difference $\Delta \mathrm{E}$ will cause higher inhibition efficiency because the energy to remove an electron from the last occupied orbital will be low [27]. For the dipole moment $(\mu)$, lower values of $\mu$ will favor accumulation of the inhibitor in the surface layer, these results agreed with Issa et al. [28].

Furthermore, the gap between the LUMO and HOMO energy levels of the molecule was another important factor that should be considered. It has been reported that excellent corrosion inhibitors are usually those organic compounds that are not only offer electrons to unoccupied orbital of the metal but also accept free electrons from the metal [29]. Table (4) indicated that AMP has the negative value for Eномо. This confirms the experimental results that interaction between AMP and aluminium is electrostatic in nature (physisorption) [26]. 


\section{Scanning electron microscopy}

Scanning electron microscopy of the aluminium samples after potentiostast examination is presented in Fig.(8). The SEM study shows that the inhibited alloy surface is found smoother than the uninhibited surface. Fig. $(8, c)$ illustrates that there was much less damage on the aluminium surface in the presence of $7.5 \times 10^{-4} \mathrm{M}$ of AMP., Accordingly, it concluded that the adsorption film was able to efficiently retard the corrosion of the aluminium.

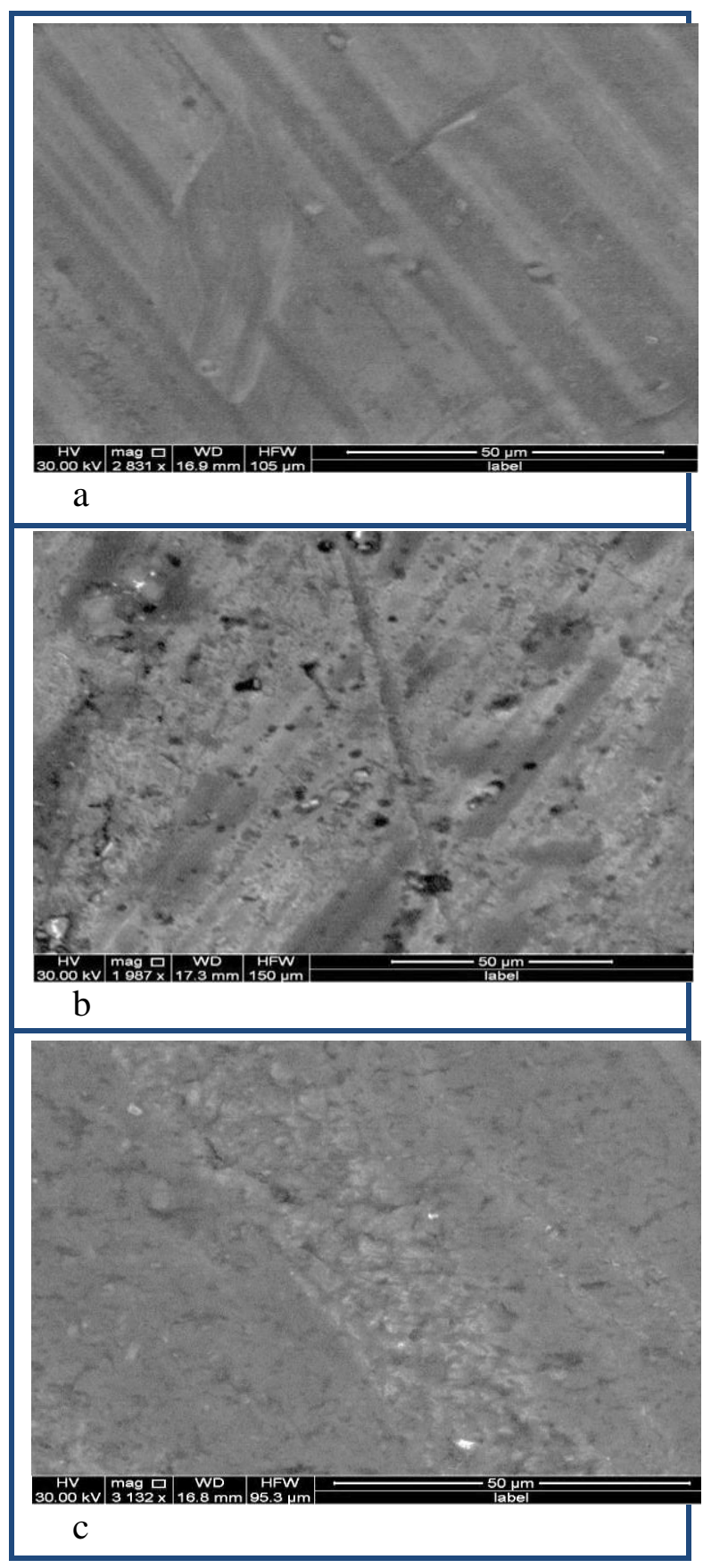

Fig.(8) Scanning electron micrographs of

(a) Polished Al alloy, (b) $3.5 \% \mathrm{NaCl}$

(c) in presence of $7.5 \times 10^{-4} \mathrm{M} \mathrm{AMP}$.

\section{Conclusion}

Results obtained from potentiodynamic polarization technique show that ampicillin acted as an effective corrosion inhibitor for aluminum alloy in sodium chloride aqueous solution with percentage inhibition efficiency obtained $85 \%$ at $7.5 \times 10^{-4} \mathrm{~mol} \mathrm{~L} \mathrm{~L}^{-1}$ AMP. Polarization result shows that ampicillin acted as a mixed type corrosion inhibitor; adsorption on the aluminum alloy surface obeys Langmuir's adsorption isotherm. The negative values of $\Delta \mathrm{G}_{\mathrm{ads}}$ show the spontaneity of the adsorption. Theoretical study confirms that ampicillin can act as inhibitor and showed good agreement with experimental results. Scanning Electron Microscopy (SEM) shows a smoother surface for inhibited alloy samples than uninhibited samples due to formation of protective barrier film.

\section{Acknowledgement}

Authors acknowledge the support from Al-Nahrain University which helped to accomplish this work; the authors also would like to thank Dr. Abdulkareem Mohammed Ali Alsamuraee, University of Baghdad, College of Science, Chemistry Department, Baghdad, Iraq, for his contribution during the experimental work.

\section{References}

[1] El-Sayed M. S., "Corrosion and Corrosion Inhibition of Aluminum in Arabian Gulf Seawater and Sodium Chloride Solutions by 3-Amino-5-Mercapto-1,2,4-Triazole", Int. J. Electrochem. Sci., 6, 1479 - 1492, 2011.

[2] Kliškić M., Radošević J., Gudić S. and Katalinić V., "Aqueous extract of Rosmarinusofficinalis L. as inhibitor of Al-Mg alloycorrosion in chloride solution" , J. Appl. Electrochem., 30, 823830, 2000.

[3] Loto C. A. and Popoola A. P. I., "Plants extracts corrosion inhibition of aluminium alloy in $\mathrm{H}_{2} \mathrm{SO}_{4}$ ", Canadian Journal of Pure and Applied Sciences, 6, 1973-1980, 2012.

[4] Abdel Rehim S. S., Hassan H. H., and Amin M. A., "Chronoamperometric studies of pitting corrosion of $\mathrm{Al}$ and (Al-Si) alloys by halide ions in neutral sulphate 
solutions," Corros. Sci., 46, 1921-1938, 2004.

[5] Abd-El-Nabey B. A., Abdel-Gaber A. M., Elewady G. Y., El. Sadeek M. M. and AbdEl-Rhman H., "Inhibitive Actionof Benzaldehyde Thiosemicarbazones on the Corrosion of Mild Steel in $3 \mathrm{M} \mathrm{H}_{3} \mathrm{PO}_{4}$ ", Int. J. Electrochem. Sci., 7, 11718 - 11733, 2012.

[6] Gece G., "Drugs: A review of promising novel corrosion inhibitors", Corros. Sci., 53, 3873-3898, 2011.

[7] Vaszilcsina N., Ordodib V. and Borzaa A., "Corrosion inhibitors from expired drugs", Int. J. Pharm., 431, 241-244, 2012.

[8] Eddib A. and Hamdani M., "Electrochemical Studies of Ampicillin as Corrosion Inhibitor for Stainless Steel in Hydrochloric Acid Solution", Mor. J. Chem., $2 \mathrm{~N}^{\circ} 3$, 165-174, 2014.

[9] Eddy N. O. and Ebenso E. E., "Corrosion Inhibition and Adsorption Characteristics of Tarivid on Mild Steel in $\mathrm{H}_{2} \mathrm{SO}_{4}$ ", E-Journal of Chemistry, 7(S1), S442-S448, 2010.

[10] Singh A., Singh A. K., and Quraishi M. A., "Dapsone: a novel corrosion inhibitor for mild steel in acid media," Open Electrochem J, 2, 43-51, 2010.

[11] Abel E. W., "The literature of inorganic chemistry," in Comprehensive Inorganic Chemistry II, J. C. Bailar, Ed., Pergamon,Oxford, UK, 1965.

[12] Rosliza R., "Improvement of corrosion resistance of aluminium alloy by natural products," in Corrosion Resistance, H. Shih, Ed.,377-395 , 2012.

[13] Shanaghi A., Rouhaghdam A. S., Shahrabi T., and Aliofkhazraei M., "Study of $\mathrm{TiO}_{2}$ nanoparticle coatings by the sol-gel method for corrosion protection", J. Mater. Sci., 44,240, 2008.

[14] Acharya S. and Upadhyay S. N., "The inhibition of corrosion of mild steel by some fluoroquinolones in sodium chloride solution", Trans Indian Inst Met., 57, 297306, 2004.

[15]Hikmat N. A., Farhan A. M. and Majed R. A., "Thermodynamic and Kinetic Parameters for Corrosion Inhibition of Al$\mathrm{Cu}$ alloy by Sodium Acetate at $\mathrm{pH} 11$ ", Know Res., 1, 62-67, 2014.
[16] Obot I. B. and Obi-Egbedi N. O., "Indeno1-one [2,3-b] quinoxaline as an effectiveinhibitor for the corrosion of mild steel in $0.5 \mathrm{M} \mathrm{H} \mathrm{H}_{2} \mathrm{SO}_{4}$ solution", Mater. Chem. Phys., 122, 325-328, 2010.

[17]Fakrudeena S. P., Murthy A. H. C and Raju B. V., "corrosion inhibition of aa6061 and aa6063 alloy in hydrochloric acid media by schiff base compounds", Chil. Chem. Soc., 57, 1364- 1371, 2012.

[18]Kosari A., Moayeda M. H., Davoodi A., Parvizi R., Momeni M., Eshghi H. and Moradi H., "Electrochemical and quantum chemical assessment of two organic compounds from pyridine derivatives as corrosion inhibitors for mild steel in $\mathrm{HCl}$ solution under stagnant condition and hydrodynamic flow" Corros. Sci., 78, 138150, 2014.

[19] Singh A. K. and Quraishi M. A., "Inhibitive effect of diethylcarbamazine on the corrosion of mild steel in hydrochloric acid" Corros. Sci., 52, 1529-1535, 2010.

[20]Zarrok H., Zarrouk A., Hammouti B., Salghi R., Jama C. and Bentiss F., "Corrosion control of carbon steel in phosphoric acid by purpald - Weight loss, electrochemical and XPS studies", Corros. Sci., 64, 243-252, 2012.

[21]Laidler K. J., Chemical Kinetics, Tata McGraw-Hill Pub. Co. New Delhi, p. 90, 1979.

[22]El-Hajjaji F., Belkhmima R. A., Zerga B., Sfaira M., Taleb M., Ebn Touhami M. and Hammouti B., "Time and Temperature Elucidation on Steel Corrosion Inhibition by 3-methyl-1-prop-2-ynylquinoxalin2(1H)-one in Molar Hydrochloric Acid: Part 2" J. Mater. Environ. Sci., 5, 263-270, 2014.

[23] Tang L. B., Mu G. N. and Liu G. H., Corros. Sci., "The effect of neutral red on the corrosion inhibition of cold rolled steel in 1.0 M hydrochloric acid", 45, 22512262, 2003.

[24]Kraka E. and Cremer D., "Computer design of anticancer drugs", J. Am. Chem. Soc., 122, 8245-8264, 2000.

[25] Gece G., "The use of quantum chemical methods in corrosion inhibitor studies" Corros. Sci., 50, 2981-2992, 2008. 
[26] John S., Ali K. M. and Joseph A., "Electrochemical, surface analytical and quantum chemical studies on Schiff bases of 4-amino-4H-1, 2, 4-triazole-3,5dimethanol (ATD) in corrosion protection of aluminium in 1N HNO3", Bull. Mater. Sci., 34, 1245-1256, 2011.

[27] Issa R. M., Awad M. K. and Atlam F. M., "Quantum chemical studies on the inhibition of corrosion of copper surface by substituted uracils", Appl. Surf. Sci., 255, 2433-2441, 2008.

[28]Zhaoa P., Liang Q. and Li Y., "Electrochemical, SEM/EDS and quantum chemical study of phthalocyanines as corrosion inhibitors for mild steel in $1 \mathrm{~mol} / \mathrm{l}$ HCl”, Appl. Surf. Sci., 252, 1596-1607, 2005.

الخلاصة

في هذا البحث تم دراسة تثتيط تأكل الألمنيوم في محلول

كلوريد الصوديوم بتركيز 3.5٪ بأستخدام عقار الأمبسلين. تم

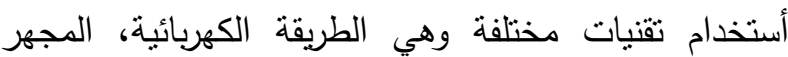

الأكتروني الماسح. وقد وجد ان الأمبسلين يقلل بصوره مؤثرة

تآكل الألمنيوم في المحلول الملحي ووجد ان كفاءة المثبط

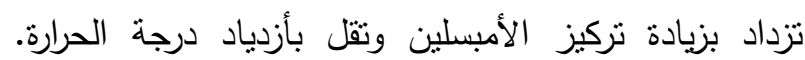

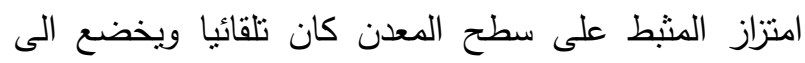

ايزوثيرم لانكماير · بعض القيم الكمية حُسبت بأستخدام

طريقة DFT وعند مستوى B3LYP/6-311G للربط بين بعني

التأثثر التثبيطي والتركيب الجزيئي للأمبيسلين. 